\title{
A systematic approach for evolving byelaws, codes and guidelines in heritage conservation areas: the use of visual simulation techniques
}

\author{
S. Basu, A. Mukerji \& V. Chatterjee \\ Department of Architecture and Regional Planning, \\ Indian Institute of Technology Kharagpur, India
}

\begin{abstract}
Protection of historic monuments and precincts of significant heritage and cultural value is commonly exercised through various legal instruments. However, each heritage monument and precinct also requires a setting to establish its context. The setting should provide an appropriate linkage to the monument and precinct, and needs some form of control mechanism to ensure that future development is sympathetic to the protected site and enhances its appreciation. In India, the 'Ancient Monuments and Archaeological Sites and Remains Act 2010', addresses this issue, to take care of the sensitive dynamics of conservation and development in areas surrounding protected monuments and precincts. This entails making Heritage Bye-laws, regulations and guidelines, with an inbuilt flexibility to cater to the changing needs and aspirations of the surrounding community, yet preserving the inherent character of the setting. This paper discusses some visual simulation methods to support formulation of such instruments, adopted in three particular cases in India. In particular, the methods contribute towards (i) conservation planning for heritage districts, (ii) formulation of site-specific byelaws based on existing scenario, (iii) assessment of visual impact of future construction, and (iv) preparation of enabling design guidelines for infill/new construction. The methodology uses view control study and visual simulation techniques as decision tools, and illustrates how translation of vernacular idioms may be employed in formulating design guidelines to ensure a consonance in built form.

Keywords: conservation bylaws, conservation regulations, conservation guidelines, infill design in heritage areas, heritage sensitive areas, view control study.
\end{abstract}




\section{Introduction}

Operational guidelines [1] for protection and management of World Heritage Sites (WHS) particularly mention provision of buffer zones and addressing the role and management of the 'setting' as a prerequisite. The expert meeting on buffer zones held at the Schatzalp in Davos, Switzerland, 2008, intended to promote reflection on the role of buffer zones for WHSs and the support they can offer to cope with new challenges and threats. Thus, an essential component of the modern conservation practices is the management of 'setting' - the historic environment of a monument /group of monuments, the significance of which is elaborated in section 2.

Management of settings involves strategies that will best sustain the heritage values of the protected precinct, and requires an understanding of likely impacts of any intervention (in the setting) on the significance and appreciation of the concerned site. The strategies would address ways and means of defining and managing the setting in consonance with its existing scenario, priorities, challenges, prevailing legal framework and organizational structure.

An integral part of management of setting is assessment of visual impact of development - pertinent because allowing gradual and harmonious transitions in the heritage setting is preferred to preserving it as frozen in time. Visual impact assessment (VIA) involves analytical approaches to systematically understand, visualize and assess impacts of interventions on visual aspects, and are important tools for an enabling development strategy. VIA is useful in evolving rationales for prescribing guidelines.

A considerable amount of studies and exercises have been done that illustrate the methods of visual impact assessment in varying contexts, some of which have provided useful learning and have been briefly reviewed in section 3 . This paper presents techniques adopted for VIA of settings of three protected monuments and precincts in India, especially in the context of the 'Ancient Monuments and Archaeological Sites and Remains Act' (AMASR Act), which was amended in 2010 to take care of the sensitive dynamics of conservation and development in areas surrounding protected monuments and precincts.

\section{Monument and its setting}

The setting of a heritage monument or precinct is a zone that in itself is not of much value or significance, but that may influence the concerned monument or precinct. The theme of 'setting' was the focus of the 15th General Assembly and Scientific Symposium of the International Council on Monuments and Sites (ICOMOS), held at Xi'an, China, in October 2005. The Xi'an Declaration [2] acknowledges that heritage structures "derive their significance and distinctive character from their meaningful relationships with their physical, visual, spiritual and other cultural context and settings", the 'setting' being defined as the 'immediate and extended environment'. In attempting to proactively guide modern development in historic places, the Declaration emphasizes that "change to the setting [...] should be managed to retain cultural significance and 
distinctive character," but such management 'need not necessarily prevent or obstruct change'. In particular, it recommends "significant skylines, sight lines and adequate distance between any new public or private development and heritage structures [...] are key aspects to assess in the prevention of inappropriate visual and spatial encroachments or land use in significant settings”.

India at present has more than 3,650 heritage monuments and sites of national importance. The settings of these are widely varying and have different challenges and issues, including encroachment, severe environmental and visual pollution, and insensitive development in the immediate vicinity of monuments. The situation is worsened due to apathy, ad-hocism, lack of awareness and absence of appropriate legal and implementation strategies, leading to interventions that defy the concept of setting. On the other hand, the settings are often inhabited areas where community provides an important link with the monument, playing a significant part in continuing the role of the monument in society.

Indian monuments, precincts and artefacts of national importance are protected and maintained by the Archaeological Survey of India (ASI) under the AMSAR Act. However, ASI's jurisdiction is only up to the boundary of the monument or precinct, designated as 'Notified Area' under the act, which may or may not include the setting of a monument. The recent amendment of the AMASR Act (2010) is concerned with the 'setting' and declares a 'Prohibited Area' of hundred metres and a 'Regulated Area' of further two hundred metres around ASI protected monuments and precincts (with provision for extension of the limit, if necessary). No new construction is permitted in the Prohibited Area, and for the Regulated Area, development is to be guided by monument-centric Heritage Bye-laws, which are to be formulated for each monument.

Formulation of the bye-laws mandates identification of attributes that are characteristic components of the heritage, objective assessment of the likely impacts of proposed development, and formulation of guidelines. Understanding inherent character of setting and promotion of a dialogue between the stakeholders regarding design implications are essential tasks in this regard, and assessment of visual impact is a necessary aspect of this process.

\section{Review of approaches for visual impact assessment}

Examination and review of some existing studies and exercises offered lessons which guided the three case studies presented in this paper. These may be briefly discussed as follows:

Goosen and Theron's [3] report for the proposed Zanzibar Urban Services Project (ZUSP) in Stone Town WHS acknowledges that Visual Impact Assessment (VIA) is important "to determine the potential visual impacts of the proposed development on potential viewers or receptors, in terms of the visual context within which the activity will take place”. The report outlines five specific steps necessary for VIA as: (i) baseline investigation, (ii) identification 
of change, (iii) assessment of resultant visual impacts, (iv) formulation of guidelines and (v) recommendation of mitigation measures.

Fairhurst [4] recommended a method for visual quality assessment, which combined visual quality attributes (views, sense of place, visual absorption capacity and aesthetic appeal) with landscape character and gave the landscape a high, medium or low visual quality value. However, in attempts to classify or score the value of something that is inherently subjective and influenced by individual interpretation, results will not be absolute and can only be measured against the criteria and parameters that have been assigned for their assessment. Fairhurst identified visibility, visual clutter and visual proportion as main aspects of visual impact. Visibility is determined by conducting a view-shed analysis to define the areas from where the development would be visible. The process involves mapping a consecutive journey through the urban area by taking photographs at significant places or at predetermined intervals. Visual clutter is a term that deals with how well the project components fit into the cultural aesthetic of the urban realm. The magnitude of the identified impacts is determined by using a rating matrix of the criteria.

The London View Management Framework [5] is a pragmatic approach for management and implementation. The View Management Plans aim to prevent undue damage to designated views, sets out appropriate development height thresholds for new development, and within identified significant view planes or panoramic views, the guidance seeks to ensure that proposed development fits within the prevailing pattern of buildings and spaces and does not detract from the panorama as a whole. A formal view analysis helps to assess the effect of the proposed development on the townscape and provides a rationale against granting consent for development which exceeds threshold heights within landmark viewing corridors or which are overly intrusive, unsightly or prominent, to the detriment of the view as a whole. Views in this case are generally not static ones, but should instead be understood as indicative of how a development will be perceived in a scene.

A systematic approach of View Control Study has been detailed out by Archaeological Services Inc. [6] for a Heritage Impact Assessment exercise in Ontario, City of Toronto. The study explains an effective implementation program that would include: (i) improved technological capacity to model protected views and to easily establish height limits within particular parcels within the area of view control, (ii) instructions to developers preparing applications within the area of view control, and (iii) provisions to protect building heights while protecting development rights through approval of appropriate densities. An aggregate level of high visual integrity was defined to determine an associated height threshold that would fully protect, to the highest extent possible, the visual integrity of significant view planes.

A recent publication by English Heritage [7] presents a method for understanding and assessing impact in terms of scale, position in a view, or design. Apart from criteria for determining magnitude of impact on heritage significance within a view, and graphics accompanying assessment, the method also considers a concept of kinetic view - how the proposed development would 
relate to heritage assets from specific assessment points and as the observer moves through the viewing place.

In general, the nature of the approaches to controlling views in relation to important heritage landmarks varies in a number of ways. Some of these approaches have been adopted to develop methodologies which were relevant in the three specific cases in India.

\section{Note on methodology}

The generic methodology for the case studies presented in this paper involves visual simulation techniques to assess impact of future construction, leading to formulation of site-specific byelaws and preparation of enabling design guidelines for infill/new construction. The visual simulations and graphics have been done with the aid of digital software suits like AutoCAD, Google Sketch Up, and CorelDRAW, with information extracted from satellite images, documentation and drawings provided by ASI, and photographic evidence. Tools for analyses inbuilt in the ArcGIS software have been used to arrive at delineation and identification of zones.

\section{Case studies}

Each of the three case studies presented here has a particular focus: the case of the old city core of Bhubaneswar involves planning for development in a heritage area; the Kanchipuram case illustrates how translation of vernacular idioms may be employed in formulating design guidelines to ensure an enabling urban development in consonance with the traditional setting; dynamic simulation technique or kinetic view study for the case of New Delhi provides rationale of bye-laws for impending high rise development in close vicinity of two important historical monuments.

\subsection{Bhubaneswar Old Town: planning for a heritage district}

The temple city of Bhubaneswar, the present State Capital of Odisha, had been an important religious and cultural centre from the 3rd century BC to the 16th century AD. Layers of historical and social circumstances have shaped the 'old town' of the city and their footprints are visible in distinct urban pattern, built heritage and living traditions, which has earned it the status of a 'Special Heritage Area' under the recently notified Comprehensive Development Plan [8]. The area has twenty-four structures and precincts protected by the ASI, and eleven others of regional significance, listed under State Archaeology Department, as well as many unlisted structures and precincts of considerable heritage value. Due to the presence of such a large number of protected sites, a complex mesh of 'Prohibited' and 'Regulated' areas are formed (following AMSAR Act), covering large parts of the old town, which were not entirely pragmatic for implementation of development regulations. The development in the immediate vicinity of protected monuments that defines the 'setting' mostly includes properties owned by private individuals or religious trusts. The 
monuments and surrounding development are intricately related not only in terms of built aspects but also in their interdependence of behavioural and socioeconomic linkages.

The primary challenge was to devise a methodology and evolve a rationale for guiding future development in the setting - meaningfully linking heritage resources with surrounding development, which would then act as a concordant setting and approach for the monuments. The three major contributions of the study may be outlined as follows:

\subsubsection{Heritage zoning}

The 'Nagara' style temples of Odisha have towers or 'Sikharas', with distinct proportion and forms. Visibility of the silhouette of the entire tower as a part of the skyline from various vantage points is important for symbolic, aesthetic and emotional values, and any high-rise development in the surrounding area should not come to be in conflict with this. A visual integrity scale that addresses conservation of the temple's silhouette was derived with this objective. The visual integrity scale in relation to contextual views was used for height zoning and subsequent delineation of heritage districts. Development 'sub-zones' were defined based on systematic analyses of the following thematic maps: (i) layout of individual plots, (ii) urban character, (iii) administrative boundary, (iv) conceptual spiritual space, and (v) movement network. Finally, the 'Prohibited' and 'Regulated' area boundaries were pragmatically re-delineated (fig. 1).

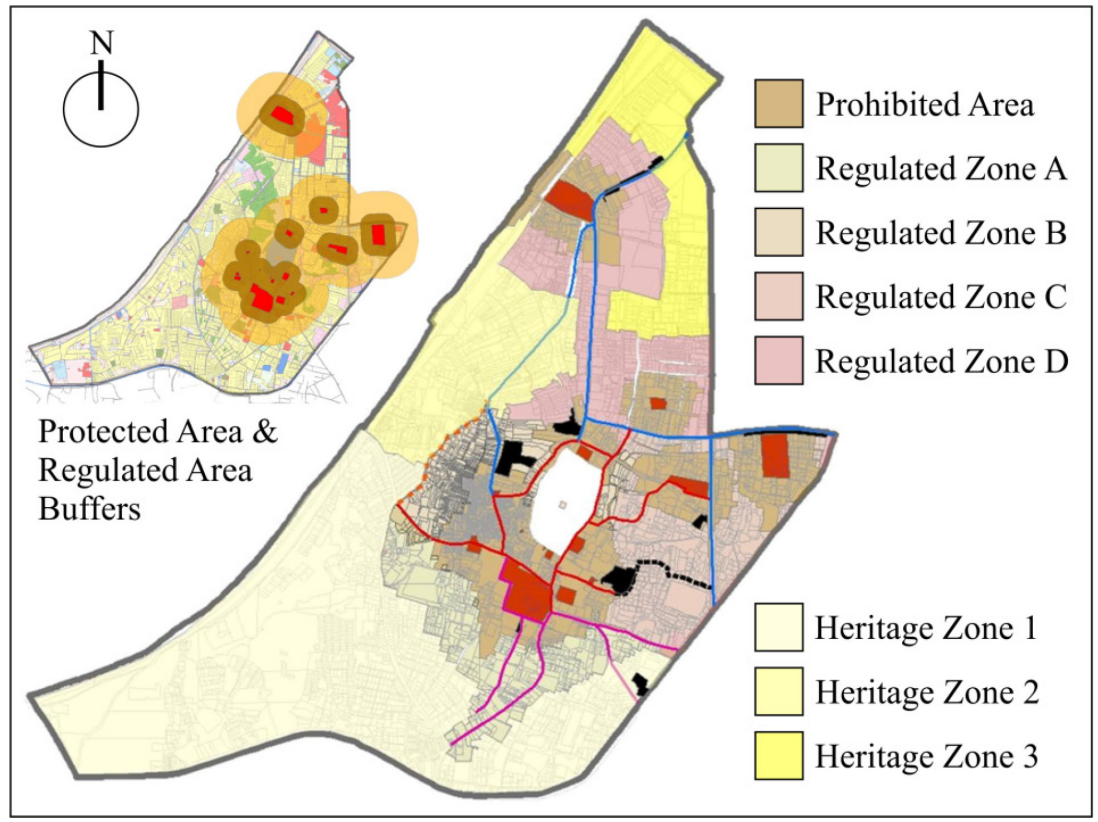

Figure 1: Delineation of sub-zones and heritage districts, Bhubaneswar. 


\subsubsection{Development bye-laws}

The Lingaraj Temple, one of the most important heritage monuments of Old Bhubaneswar, is of high significance for its architectural, historical and symbolic values. Towering above the existing cityscape, it is visible from a distance, and its importance as a landmark on the skyline was the determining factor for identification of significant views. Important view-planes were identified along processional routes, various approach roads, and in relation to the central water body (fig. 2). This exercise revealed that the 'regulated sub-zones B' provided a very strong visual linkage to the temple. However, the roads were not straight, and visibility of the temple tower changed with road curvature. To anticipate, measure, and respond to potentially negative impacts of possible development on views associated with the temple, a sequential recording and mapping of the changing streetscape was done .This was superimposed with varying heights of development through digital $3 \mathrm{D}$ visual simulation techniques to generate alternative scenarios (fig. 3) which indicate:

(i) Original visual linkages with height of structures restricted to eight metres and predominant silhouette in view - ideal situation , high visual integrity;

(ii) Existing visual linkages with height of structures eleven metres and only the top most part in view - minimal visual integrity;

(iii) Emerging trend of fourteen metres high structures with loss of visual linkages - loss of visual integrity.

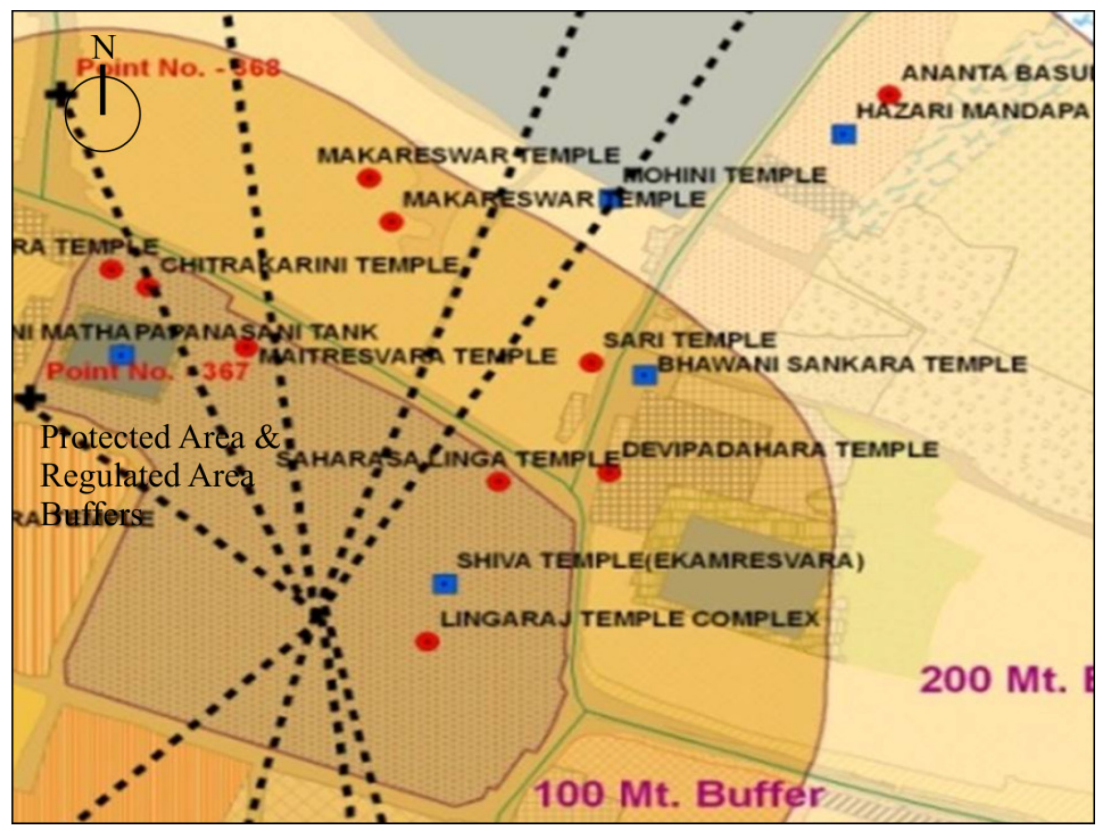

Figure 2: $\quad$ Identification of significant view-planes for Lingaraj temple. 


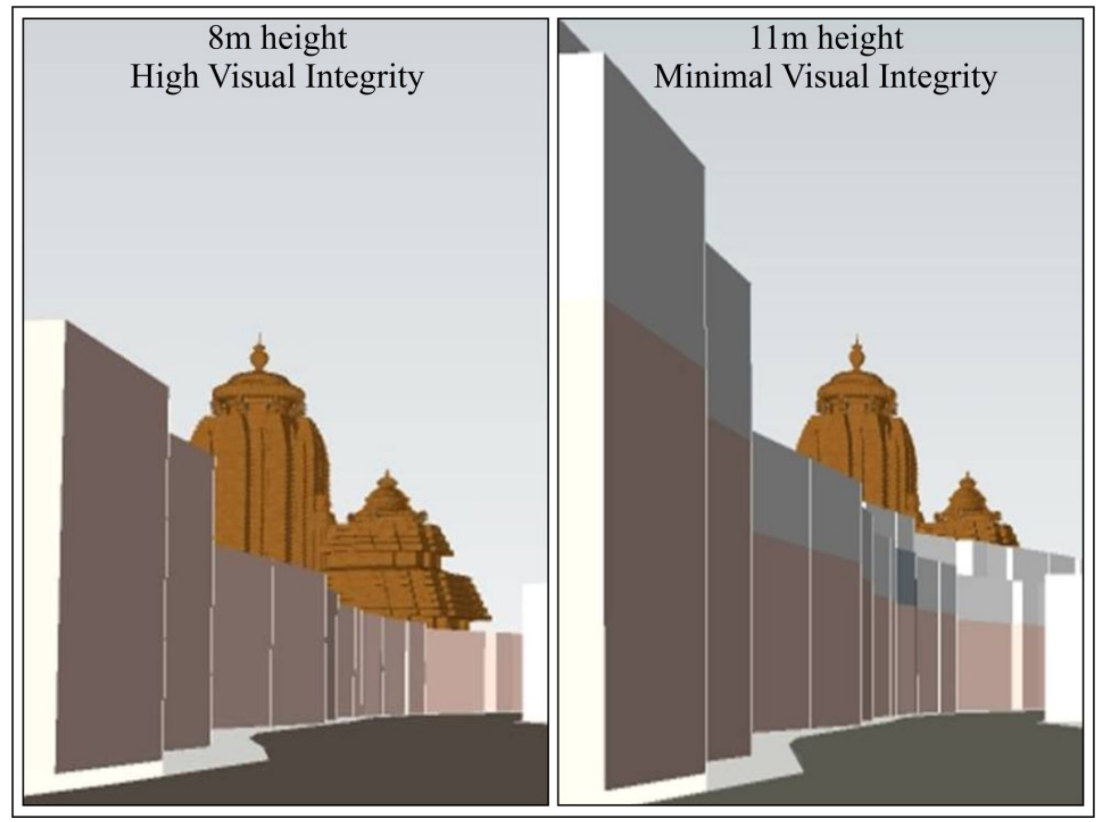

Figure 3: $\quad$ Simulation of development scenarios for Bhubaneswar.

However, further investigation revealed that a level of moderate visual integrity may be achieved in case the upper floors were recessed, depending on road width and road geometry. For a road with fourteen metres right of way (ROW), a structure may be permitted to be build up to a height of fourteen metres with a mandatory setback of two and a half metres for the topmost floors. For ROW less than fourteen metres, the maximum permissible height should not exceed ten metres.

\subsubsection{Design guidelines}

New constructions are generally governed by bye-laws that prescribe maximum permissible height, coverage, Floor Area Ratio (FAR) and setback. However, to ensure harmonious development in a Heritage Character Zone (HCZ), it is necessary to also prescribe design principles based on existing urban fabric and building characteristics in the HCZ. General design principles need to address:

(i) building form, rather than architectural style, (ii) façade demarcation, (iii) building material, (iv) proportion and percentage of openings, and (v) building setback. To ensure innovative building designs and materials which are compatible with the site's context, acceptable infill design was demonstrated using simulation techniques and the concept of best-fit slide - a simple graphic appraisal method. This approach of developing design guidelines beyond the basic bye-laws is further elaborated in the case study of Kanchipuram. 


\subsection{Kanchipuram: translation of vernacular idioms to evolve guidelines in a historic context}

Kanchipuram, known as city of thousand temples, has magnificent temples of unique architectural beauty, bearing eloquent testimony to its glorious Dravidian heritage exemplified by ASI protected monuments like Sri Mukthiswara Temple and Jvaraheswara Temple. Areas around temples have a distinctive identity, as entire streets were once occupied by the traditional row houses (Agraharam) of Brahmins (the priest community). Agraharam architecture is distinctive with sloping roofs of country-tiles, Burma teak rafters and lime plastering. Most houses had entrance platforms lined with circular timbre columns along the street façade, and an open to sky court in the centre. The pressures due to urban growth demand single storied houses to be replaced by multi-storied structures.

To provide a harmonious development sensitive to the setting, innovative design solutions for infill had to be encouraged. Design guidelines with explanatory notes were developed to indicate how essential elements of the traditional architecture may be translated into contemporary designs through systematic analysis of building form (rather than architectural style), façade demarcation, proportion, details, fenestration design, and colour schemes. This was communicated through explanatory graphics (fig. 4) and demonstrative digital visual simulations of alternatives to existing and proposed development (fig. 5).

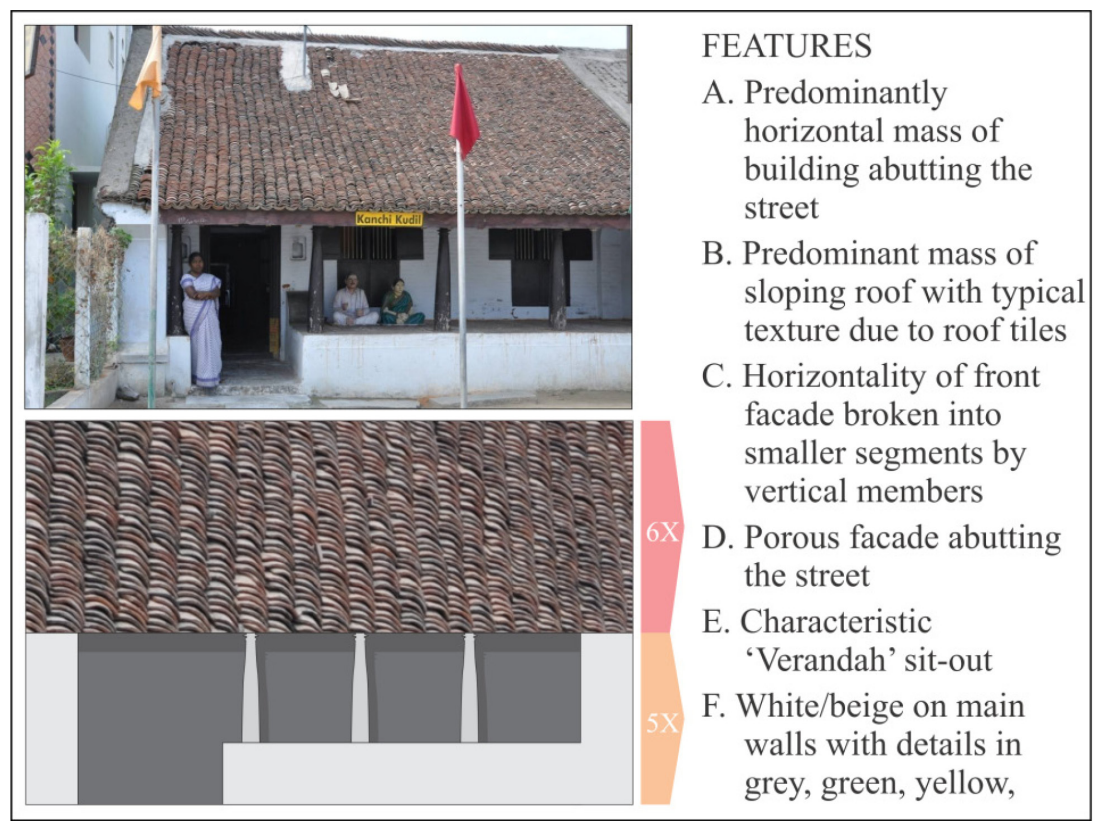

Figure 4: Translation of vernacular idioms of Agraharam architecture, Kanchipuram. 


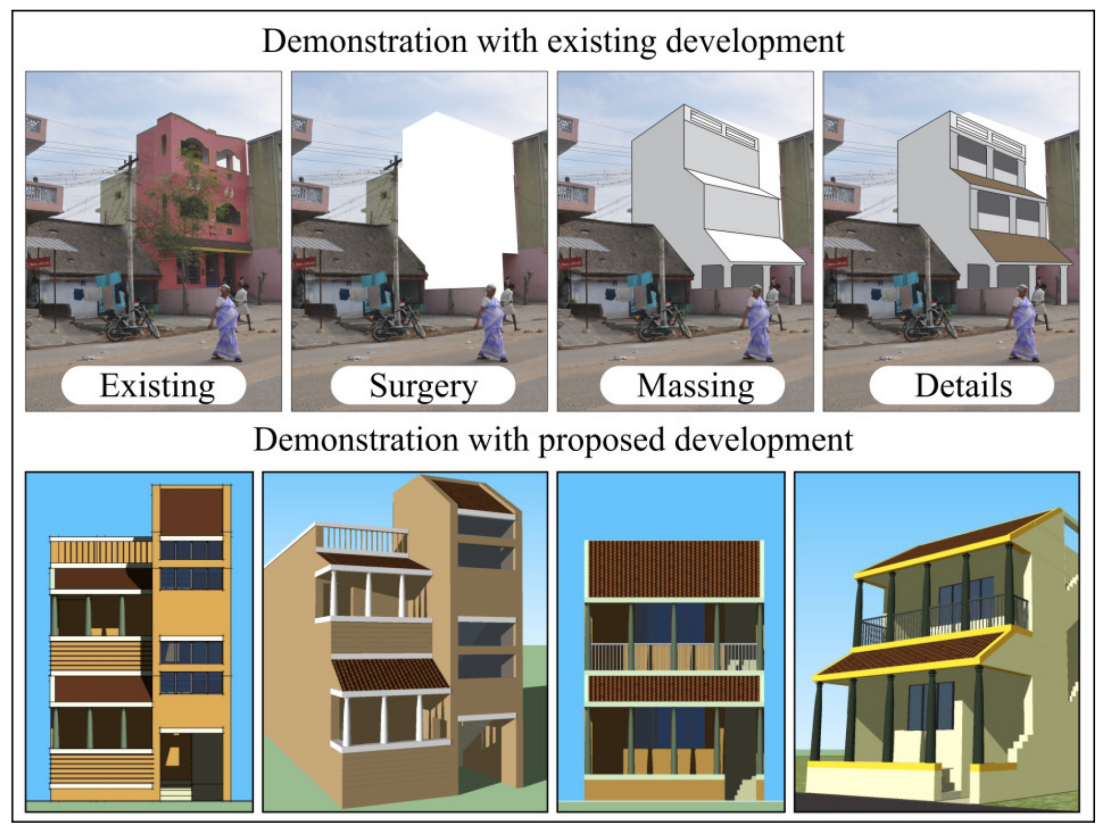

Figure 5: Simulation of alternatives to existing/proposed development, Kanchipuram.

\subsection{Sher Shah Gate, New Delhi: a kinetic view study}

The Sher Shah Gate, New Delhi, is believed to be the southern gateway of Sher Shah's walled city, Shergarh - an important historical footprint in New Delhi, the capital city of India. The access to the monument is through a historic promenade to the south of the gate with remains of arcades that might have been rows of shops. The precinct is protected under ASI, but it is surrounded by major roads, important civic buildings and residential areas of the present day capital, and there are pressures of developing adjacent properties to increased floor area. As per AMASR Act, monument-specific Heritage Bye-laws were to be formulated to regulate development in the vicinity, so as to retain its grandeur and importance as an important historic landmark. To arrive at the desirable height to be prescribed for a particular zone in its vicinity, a dynamic simulation study was conducted, analyzing the impact of various levels of increased heights of properties adjacent to the monument, described as follows.

The monument was digitally simulated to scale in 3D, and three different development scenarios were generated by extruding the existing building footprints of the institutional complex in the zone immediately abutting the precinct - up to $18 \mathrm{~m}, 21 \mathrm{~m}$ and $24 \mathrm{~m}$ (fig. 6). Four relevant viewpoints were revealed by a dynamic simulation of possible movement around the precinct. 


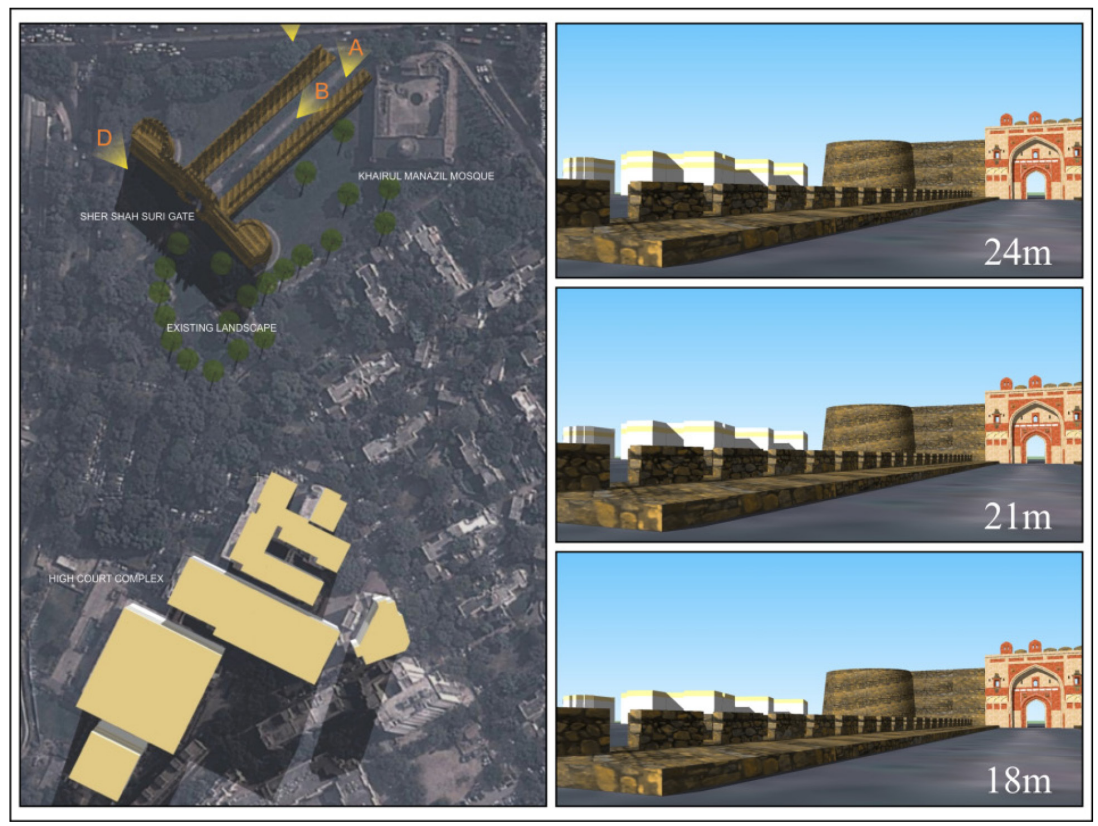

Figure 6: Simulation of development scenarios around Sher Shah Gate, New Delhi.

Visual impact of the development scenarios on the appreciation of the monument's skyline and distinctive features was assessed from these four selected viewpoints and associated movement paths. The study recommended an allowable height of $21 \mathrm{~m}$ for the Heritage Bye-laws of the zone, which would ensure that the visual integrity of the monument is not compromised.

\section{Conclusion}

Settings of historic monuments and precincts are sensitive areas and need careful understanding of the relationships that exist between the monuments and their surroundings. Changes are not entirely undesirable but these need to be assessed with respect to impacts of the proposed changes on the significance and unique values of the monuments within a particular context. Factors like visibility, visual integrity, impact of height, mass, scale et cetera contribute to the visual experience and have lasting impacts that need to be controlled, regulated and guided by appropriate legal instruments. On the other hand, excessive control and stringent guidelines often lead to antagonism and mistrust amongst stakeholders. Transparency and rational analysis are essential to establish a dialogue for bringing in changes that are harmonious, sympathetic, logical in approach, and enabling in intentions. View control study in various forms, kinetic view study, and simulation techniques to understand impacts of various 
scenarios, as conducted for Bhubaneswar and New Delhi, help to formulate guidelines systematically and rationally.

Much like Kanchipuram, many Indian towns still exhibit the presence of strong vernacular idioms in their existing built-form, and these structures contribute to distinct townscape values. Due to changing urban dynamics, old buildings are indiscriminately being demolished to be replaced with structures that do not have any relevance to the vernacular idioms, thus erasing the distinct identity built over centuries. Apart from mandatory Heritage Bye-laws, these areas need guidelines that can easily be communicated to the residents, local authorities and design practitioners, and visual simulation techniques prove worthwhile in this regard.

\section{References}

[1] Operational Guidelines for the Implementation of the World Heritage Convention (WHC.12/01); United Nations Educational, Scientific and Cultural Organisation (UNESCO), July 2012. http://whc.unesco.org /archive/opguide12-en.pdf

[2] Xi'an Declaration on the Conservation of the Setting of Heritage Structures, Sites and Areas; International Council on Monuments and Sites (ICOMOS), October 2005. http://www.international.icomos.org/xian2005/xiandeclaration.htm

[3] Goosen, J. and Theron, G., Executive summary. Visual Impact Assessment, for inclusion in the environmental and Social Impact Assessment (ESIA) for the Zanzibar Municipal Council's proposed Zanzibar Urban Services Project (ZUSP), Report Number 12574-9424-4, Golder Associates, February 2010

[4] Fairhurst, K., Visual Landscape Design Approaches (Forestry 491), Faculty of Forestry, University of British Columbia, p.21, October 2008. http://faculty.forestry.ubc.ca/sheppard/frst491/FRST491_2008_files/Frst491 _Fairhurst_Design_2008.pdf

[5] The London View Management Framework (LVMF) SPG, 2007. http://legacy.london.gov.uk/mayor/strategies/sds/docs/spg-views-finalall.pdf

[6] Archaeological Services Inc. Heritage Impact Assessment: View Control Study, Queen's Park and Ontario Legislative Assembly Building, prepared for City Planning Division, City of Toronto, (ASI File 09SP-55), pp. 67-71, November 2009. http://www.arconserv.ca/news_events/cf_download.cfm? file=Final\%20HIA_Viewshed.pdf\&path=\%5C

[7] English Heritage. Seeing the History in the View: A Method for Assessing Heritage Significance within Views, pp. 22-26, May 2011. http://www.english-heritage.org.uk/publications/seeing-history-view/seeinghistory-in-view.pdf

[8] Comprehensive Development Plan for Bhubaneswar Development Plan Area 2030, Department of Architecture \& Regional Planning, IIT Kharagpur: Kharagpur, India, 2010 